\title{
Los fieles miembros de ordinariatos para antiguos anglicanos y su incorporación a la diócesis
}

\section{The Faithful of Ordinariates for Former Anglicans and their Incorporation into the Diocese}

\section{José María Chiclana Áctis}

Doctor en Derecho Canónico

Pamplona

josemariachiclana@gmail.com

Resumen: Los ordinariatos personales para fieles provenientes del anglicanismo están abiertos a aquellos anglicanos que individual o corporativamente quieren ser recibidos en la Iglesia católica manteniendo sus tradiciones pastorales, litúrgicas y espirituales. En este artículo se analiza quiénes pueden ser miembros de un ordinariato personal y si los fieles de un ordinariato son también fieles de la diócesis donde tienen su domicilio o quasidomicilio.

Palabras clave: Anglicanorum Coetibus, Ordinariatos personales, Jurisdicción exclusiva.
Abstract: Personal Ordinariates for faithful coming from Anglicanism are open to those Anglicans who want to be individually or collectively received into the Catholic Church while retaining their pastoral, spiritual and liturgical heritage. This article explores who may become a member of a Personal Ordinariate, and if the faithful of the Ordinariate are also faithful of the diocese where they are domiciled or quasi-domiciled.

Keywords: Anglicanorum Coetibus, Personal Ordinariates, Exclusive Jurisdiction. 
E n noviembre de 2009, con la Constitución Apostólica Anglicanorum Coetibus (en adelante AC), el papa Benedicto XVI creaba los Ordinariatos Personales para fieles provenientes del Anglicanismo ${ }^{1}$ para acoger corporativamente en la Iglesia católica a fieles provenientes de esta Comunidad Eclesial. Aparte de AC se recogían en un documento posterior llamado Normas Complementarias (en adelante NC) algunos otros aspectos. Por su parte, cada ordinariato personal erigido tiene un decreto de erección ${ }^{2}$. Aunque es muy similar en los tres primeros casos, regulan algunos aspectos de la vida de los ordinariatos. Además, cada ordinariato ha ido aprobando reglamentos y normas internas. Por último, la Santa Sede ha aprobado también normas litúrgicas referentes al sacramento del matrimonio, la celebración de exequias y, un nuevo Misal publicado en noviembre de 2015. Desde la promulgación de la Constitución Apostólica se han creado tres Ordinariatos Personales: el primero en Inglaterra; The Personal Ordinariate of Our lady of Walshingham (en adelante OLW), el 15 de enero de 2011. Otro en Estados Unidos; The Chair of Saint Peter (en adelante OCTP), el 1 de enero de 2012 y otro en Australia; Our Lady of the Southern Cross, el 15 de junio de 2012 (en adelante OLSC).

Desde su creación los ordinariatos personales han crecido. En Reino Unido cuentan aproximadamente con 81 sacerdotes y alrededor de 2.500 lai$\cos ^{3}$ (en 2013, 57 sacerdotes y 1.500 laicos ${ }^{4}$ ) con 60 comunidades en Inglatera y 4 en Escocia ${ }^{5}$. Tienen en propiedad dos iglesias y cuentan también con

${ }^{1}$ Para simplificar y por razones de brevedad, en el ámbito de este artículo me referiré a los «Ordinariatos Personales para fieles provenientes del Anglicanismo», con la expresión «ordinariatos personales» y a sus ordinarios con el nombre de «ordinarios personales», consciente de que esos nombres no son exclusivos de estos supuestos y que son sólo un caso entre otros posibles de aplicación de la figura del ordinariato personal y del ordinario personal. Por tanto, al usar esa expresión abreviada no pretendo que las afirmaciones que puedan ser válidas específicamente para el supuesto que aquí se estudia sean extensibles a los demás casos posibles de ordinariatos personales.

2 En adelante los citaremos en nota al pie de la siguiente manera: DEPOOLW (Decreto de erección del Ordinariato de Our Lady of Walsingham), DEPOTCSP (Decreto de erección del Ordinariato de The Chair of Saint Peter) y DEPOOLSC (Decreto de erección del Ordinariato de Our Lady of the Southern Cross).

3 Cfr. Anuario Pontificio 2014, 1034. Aunque en una entrevista en septiembre de 2015 en The Portal el canciller del ordinariato Jonathan Redvers Harris comentaba que cuenta con unos 1.500 laicos y 90 sacerdotes y que el ritmo de adscripción es de una persona a la semana de media. El texto completo de la entrevista, publicada en la revista oficial del Ordinariato de Our Lady of Walshingham, The Portal, October 2015, 19-20, puede leerse en www.portalmag.co.uk/portal/ portal.pdf (acceso 2/8/2016).

4 Cfr. Anuario Pontificio 2013, 1034.

5 www.ordinariate.org.uk/groups/groups.html (acceso 25/3/2017). La web www.catholic-hierarchy.org/diocese/dgbpo.html (acceso 27/3/2017) ofrece los datos de 3.500 laicos y 86 sacerdotes. 
dos comunidades religiosas, procedentes del anglicanismo, que son ahora comunidades católicas.

En Estados Unidos alrededor de 29 sacerdotes y 4.550 laicos $^{6}$ (en 2013, 23 sacerdotes y 2.250 laicos $^{7}$ ) repartidos en 42 comunidades en Estados Unidos y 4 en Canadá. Hay también una comunidad religiosa, una casa de formación para seminaristas propios y el ritmo de recepción y ordenación de sacerdotes de antiguos ministros anglicanos va aumentando poco a poco'. El ordinariato de Australia cuenta con unos 10 sacerdotes y 1.000 laicos $^{10}$ (en 2013, 7 sacerdotes y 300 laicos $^{11}$ ) con 12 comunidades en Australia y dos en Japón ${ }^{12}$.

Desde que en 1833 se iniciara el Movimiento de Oxford han sido numerosos los desarrollos y esfuerzos que miran hacia una unión de las comunidades eclesiales congregadas en la Comunión anglicana con la Iglesia católica. Las más importantes han sido las Conversaciones previas a la Bula Apostolicae Curae (1889-1896), las Conversaciones de Malinas (1921-1927) y los encuentros de la Anglican Roman Catholic International Commission (ARCIC) (1966-2015 ${ }^{13}$ ). Sin embargo, aunque la Constitución Apostólica Anglicanorum Coetibus tiene importantes efectos ecuménicos, no es una acción en la misma línea de estos encuentros. Con la erección de los ordinariatos personales la Iglesia católica ofrece una respuesta concreta a las solicitudes particulares que ha recibido de diversos grupos de anglicanos desde 1977 en Estados Unidos y desde 1992 en Inglaterra. Solicitudes que se produjeron a raíz de los cambios doctrinales en la Comunión anglicana como la relativización del uso de medios anticonceptivos, la admisión de mujeres al ministerio presbiteral y episcopal, el cambio en los cánones sobre el divorcio, las diversas posturas sobre el aborto o la aprobación de una serie de revisiones en el Book of Common Prayer. Fueron los puntos finales de una evolución que llevaría a diversos grupos de Episcopalianos en Estados Unidos y de Anglicanos en Inglaterra a acercarse a la Iglesia católica y solicitar ser recibidos en ella

\footnotetext{
${ }^{6}$ El Anuario Pontificio de 2014 daba el dato de 23 sacerdotes (cfr. Anuario Pontificio 2014, 1034). El 31 de agosto de 2015 fueron ordenados cuatro más, y en junio de 2016, otros dos más (cfr. http://ordinariate.net/news?page=1 [acceso 2/8/2016]).

7 Cfr. Anuario Pontificio 2013, 1034.

8 www.ordinariate.net/parishfinder (acceso 25/3/2017).

9 Se pueden ver algunos datos en www.ordinariate.net/documents/2015/6/une2015magazine. compressed.pdf (acceso 25/3/2017).

${ }^{10}$ Cfr. Anuario Pontificio 2014, 1034.

${ }^{11}$ Cfr. Anuario Pontificio 2013, 1034.

12 www.ordinariate.org.au/Congregations/congregations_qld.htm (acceso 25/3/2017).

13 La última reunión tuvo lugar en mayo de 2015 (www.anglicancommunion.org/media/163280/ ARCIC-III-Villa-Palazzola-2015.pdf [acceso 27/3/2017]).
} 
como una estructura autónoma dentro de la Iglesia católica, manteniendo su atención pastoral particular y sus tradiciones litúrgicas y espirituales ${ }^{14}$.

Desde el punto de vista jurídico, desde el inicio de esta nueva figura se planteó la cuestión sobre quiénes pueden ser miembros de estos nuevos ordinariatos y si al formar parte de un ordinariato personal ese fiel es también miembro de la diócesis donde tiene su domicilio o si puede formar parte de otras circunscripciones. El segundo punto es el que deja de momento más cuestiones abiertas. Para ello veremos en primer lugar quiénes pueden formar parte de un ordinariato personal y en segundo lugar si los fieles de un ordinariato personal son también fieles de la diócesis.

\section{QUIÉNES PUEDEN SER FIELES DE UN ORDINARIATO PERSONAL}

Para ser miembro de un ordinariato personal ha de realizarse una declaración de voluntad por escrito ${ }^{15}$. En principio el acceso es restringido precisa-

${ }^{14}$ Desde 1977 en Estados Unidos, tras la aprobación de la admisión de mujeres al ministerio presbiteral, varios grupos pidieron a la Santa Sede ser recibidos manteniendo sus tradiciones como grupo. Esas peticiones darían lugar a la Pastoral Provision, creada en 1981 y vigente hasta hoy, aunque ya en declive por la aparición de los ordinariatos. Sucesivamente, en 1995, 1997 y 2006, varios grupos de episcopalianos solicitan ser recibidos en la Iglesia católica de forma corporativa. En Inglaterra desde 1992, a raíz de la aprobación de la admisión de mujeres al ministerio anglicano en la Iglesia de Inglaterra, varios grupos de anglicanos solicitan ser recibidos en la Iglesia católica como una Prelatura Personal o como una estructura jurídica que permitiese mantener sus tradiciones y su atención pastoral. En 1995 se aprobó una medida pastoral (The Statutes for the Admission of Married Former Anglican Clergymen into the Catholic Church) para recibir a ministros anglicanos y que fueran ordenados en la Iglesia católica. Sucesivamente, desde 2005 hasta 2009, se produjeron una serie de conversaciones y solicitudes por parte de grupos de anglicanos con la Santa Sede. Los grupos y personas que realizaron estas solicitudes son variados y su influencia en la promulgación de AC es también diversa. La primera solicitud provino de la Tradicional Anglican Communion (TAC) en 2007, que inició sus primeros contactos en 2005. También tuvieron lugar contactos desde Forward in Faith, e igualmente, entre octubre de 2008 y noviembre de 2009, tuvieron lugar conversaciones entre un grupo de anglicanos (obispos y ministros) y miembros de la CDF donde se discutió el contenido concreto de AC. Para todo ello cfr. W. TigHe, The Genesis of Anglicanorum Coetibus, Anglican Embers, vol. III, number 8, advent 2011, 347-364; C. BRAND, That Nothing Be Lost: America, Texas, and the Making of Anglicanorum Coetibus, Catholic southwest 22 (2011) 48-67; W. OdDIE, The Roman Option, Harper Collins, Londres 1997; J. M. ChicLana, La Constitución Apostólica Anglicanorum Coetibus: Los ordinariatos personales para fieles provenientes del anglicanismo (Tesis de Doctorado, Universidad de Navarra, 4-X-2013, pp. 27-108).

15 Art. IX de AC. Puede verse un ejemplo de los formularios que se utilizan en el Ordinariato de Our Lady of Walsingham en www.ordinariate.org.uk/cmsAdmin/uploads/application_enrollment_(catholic).pdf (acceso 10/2/2016) o el de The Chair of Saint Peter, que ofrece formularios también para familias enteras, o comunidades, en cuyo caso ha de realizarse también individualmente (www.ordinariate.net/resources/ [acceso 12/2/2016]). 
mente por la finalidad de la ley: facilitar la plena comunión de fieles individuales y de aquellas comunidades anglicanas que lo deseen con la Iglesia católica. Señala AC I $\$ 4$ que «El Ordinariato está formado por fieles laicos, clérigos y miembros de institutos de vida consagrada o de sociedades de vida apostólica, originariamente pertenecientes a la Comunión anglicana y ahora en plena comunión con la Iglesia católica, o que reciben los sacramentos de la iniciación en la jurisdicción del Ordinariato mismo».

Por su parte, las Normas Complementarias art. $5 \$ 1$ in fine señalan que «de ordinario, quienes fueron previamente bautizados como católicos fuera del Ordinariato no pueden ser admitidos como miembros, a no ser que sean miembros de una familia que pertenezca al Ordinariato».

$\mathrm{Al}$ contener este artículo las palabras «de ordinario», podríamos pensar que existen dos modos de incorporación al ordinariato: el ordinario y el extraordinario ${ }^{16}$. El modo ordinario de incorporación incluiría los casos previstos en la ley y el extraordinario, los no previstos. Sin embargo, la traducción al castellano del término inglés ordinarily del texto oficial promulgado creo que no expresa bien el significado: En inglés, esta expresión no se está refiriendo al concepto jurídico de forma extraordinaria de incorporación, como si existiesen dos vías procesales fijas (ordinaria y extraordinaria) a través de las que -cumpliendo una serie de requisitos- un fiel puede y debe ser admitido en el ordinariato. La expresión ordinarily se refiere a que los fieles que pueden incorporarse a un ordinariato son solamente aquellos que prevé la ley pero que pueden existir casos excepcionales en los que el ordinario puede aceptar la solicitud de un fiel que quiere incorporarse al ordinariato pero que no entraría en los casos previstos por la ley ${ }^{17}$. Se trataría más bien de excepciones a la ley, no de un modo extraordinario de incorporación. Veamos estos dos modos de incorporación al ordinariato.

\subsection{Modo ordinario de incorporación}

De modo ordinario pueden incorporarse a un ordinariato:

${ }^{16}$ E. BAURA, Las circunscripciones eclesiásticas personales: el caso de los ordinariatos personales para fieles provenientes del anglicanismo, Ius Canonicum 50 (2010) 165-200, 194 y también J. M. Díaz MoRENO, Constitución «Anglicanorum Coetibus» sobre la institución de Ordinariatos personales para los anglicanos que ingresan en la plena comunión con la Iglesia, Revista Española de Derecho Canónico 67, 168 (2010) 427, nota 36.

17 En esta misma línea, cfr. J. Huels en Canonical comments on Anglicanorum Coetibus, Worship, Edited by Benedictines of St. John's Abbey (MN. USA) 84 (2010) 237-253 y 240. 
a) Laicos, clérigos y miembros de institutos de vida consagrada o de sociedades de vida apostólica originariamente pertenecientes a la Comunión anglicana que ya están -desde hace mucho o poco tiempo- en plena comunión con la Iglesia católica (AC I $§ 4)$.

b) Laicos, clérigos y miembros de institutos de vida consagrada o de sociedades de vida apostólica originariamente pertenecientes a la Comunión anglicana que reciben alguno de los sacramentos de iniciación en la jurisdicción del Ordinariato y son recibidos en la Iglesia católica (AC I \$4).

c) Cualquier persona que reciba el bautismo (y los demás sacramentos de iniciación si es el caso) en la jurisdicción del Ordinariato (AC I \$4).

d) Bautizados en la Iglesia católica que abandonaron la fe y vuelven a ella por la actividad apostólica de un ordinariato y reciben la confirmación o la eucaristía o ambos sacramentos en la jurisdicción del ordinariato (NC art. $5 \$ 2$ ).

e) Laicos, clérigos y miembros de institutos de vida consagrada o de sociedades de vida apostólica bautizados en la Iglesia católica fuera de la jurisdicción del ordinariato que sean «miembros de una familia del ordinariato» (NC art. $5 \$ 1)$.

Veamos algunas cuestiones que se plantean.

\subsection{La expresión fieles «originariamente pertenecientes a la Comunión anglicana»}

$\mathrm{Al}$ referirse la ley a fieles «originariamente pertenecientes a la Comunión anglicana y ahora en plena comunión con la Iglesia católica» (AC I \$4) incluye a aquellos fieles anteriormente pertenecientes a una church, congregation o society de raíz o tradición anglicana, que ya fueron recibidos en la Iglesia católica hace tiempo. También a aquellos que fueron recibidos en la Iglesia católica en previsión de la futura -pero en su momento incierta- erección de un ordinariato personal en su país ${ }^{18}$. Es decir, cualquier fiel procedente de la Co-

${ }^{18}$ Por ejemplo el 9 de octubre de 2011, coincidiendo con la fiesta del Beato Newman, unos 80 fieles de la Parroquia de St. Luke, en Bladensbrug, Maryland, fueron recibidos uno a uno en la Iglesia católica, en una ceremonia celebrada por el Cardenal Wuerl, en previsión de incorporarse a un ordinariato personal que se erigiera en Estados Unidos. El pastor de la parroquia, Mark Lewis, se encontraba entre los fieles recibidos y comenzaba entonces su preparación para ser ordenado como sacerdote católico. Dos semanas antes, el 25 de septiembre, unos 30 miembros de otra pa- 
munión anglicana ya recibido en la Iglesia católica, puede ser miembro de un ordinariato personal. El criterio que se utiliza en la práctica es que el fiel pueda demostrar que tiene un «cierto background anglicano» ${ }^{19}$.

Es lógico que este grupo de fieles sean los primeros que menciona la ley. Ha de tenerse en cuenta que muchos de estos fieles que fueron recibidos en la Iglesia católica -muchos de ellos desde los primeros acercamientos de grupos de episcopalianos en 1977 en Estados Unidos o en 1992 en Inglaterra-, hubieran deseado poder mantener estas tradiciones litúrgicas, espirituales y pastorales de la Comunión anglicana, pero en su momento, no fue posible.

En los tres primeros decretos de erección de ordinariatos personales también se ha querido especificar esta posibilidad referida a los clérigos ${ }^{20}$ para que quede claro que es posible la incardinación de aquellos sacerdotes católicos que eran ministros anglicanos y que ya habían sido recibidos en la Iglesia católica desde 1981 en Estados Unidos con la Pastoral Provision ${ }^{21}$ y en Inglaterra desde 1995 a través de los Statutes for the Admission of Married Former Anglican Clergymen into the Catholic Church ${ }^{22}$. Aunque esta opción era algo previsto ya por el c. 267, pienso que ha querido introducirse en la ley para facilitar el camino y que el paso de estos sacerdotes de una diócesis al ordinariato sea sencillo.

rroquia anglicana, la de St. Peter on the Rock, de Fort Worth, en Texas, habían sido recibidos en la Iglesia católica como el primer grupo que formaría parte de un Ordinariato Personal para Estados Unidos. Dos pastores anglicanos se encontraban en el grupo de 30 fieles. Ambos comenzaron su formación sacerdotal en la Iglesia católica para ser los futuros sacerdotes de esa parroquia.

19 En el Ordinariato de The Chair of St. Peter tienen ese criterio. Con la expresión background anglicano se hace referencia a grupos que hayan mantenido cierta unión con Canterbury, o que si la dejaron, hayan mantenido el núcleo de las tradiciones anglicanas. Hay multitud de grupos, pero es normal que se sepa cuál es el credo que aceptan, la doctrina, etc.

${ }^{20} \mathrm{El} \mathrm{n} .7$ de los tres primeros decretos señala «A cleric, having come originally from the Anglican Communion, who has already been ordained in the Catholic Church and incardinated in a Diocese, is able to be incardinated in the Ordinariate in accord with the norm of c. 267 CIC».

${ }^{21}$ Desde julio de 1981 hasta diciembre de 2012 fueron ordenados 107 sacerdotes en el proceso de la Pastoral Provision de los cuales, unos 12 son célibes, el resto casados. Cfr. P. Sullings, The Pastoral Provision Priests in the American Catholic Presbyterate (pro manuscripto), 3.

22 Pueden consultarse los Estatutos completos en Briefing (revista de documentos de la Conferencia Episcopal de Inglaterra y Gales) de 20 de julio de 1995, 8-9 (Briefing dejó de editarse). También están disponibles en Origins, n 9, vol. 25, 27 July 1995, 146-148 y en Ius Ecclesiae 8 (1996) 377-380. Aunque las fuentes no son precisas y no hay datos oficiales, según Peter Geldard involucrado en estos procesos, desde 1992 hasta 2007, en Inglaterra han sido ordenados como sacerdotes católicos 580 antiguos anglicanos procedentes de la Iglesia de Inglaterra, de los cuales, 120 están casados. Otros 150 antiguos pastores no han sido ordenados y fueron recibidos como laicos, cinco ministros anglicanos pasaron a la Iglesia Ortodoxa y otros siete pasaron a diversos continuing movements anglicanos. Cfr. P. GELDARD, Conversion and enrichment, en S. CAVANAUGH (ed.), Anglicans and the Roman Catholic Church, Ignatius Press, San Francisco 2011, 40-63, 57. 


\subsection{Los fieles de las parroquias de Uso Anglicano de la Pastoral Provision}

En 1981 la Santa Sede creó la Pastoral Provision para acoger a fieles provenientes de la Iglesia Episcopal en Estados Unidos. En algunas diócesis se erigieron parroquias personales donde se conservaban algunas tradiciones espirituales, pastorales y litúrgicas acordes con la doctrina católica ${ }^{23}$.

Una cuestión que ha suscitado algunas dudas es si en el apartado fieles «originariamente pertenecientes a la Comunión anglicana» se incluyen también a todos aquellos fieles que no provienen de la Iglesia Anglicana pero son miembros de estas parroquias. El caso es que en estas parroquias católicas hay variedad de fieles. En primer lugar fieles que provienen del anglicanismo y también muchos fieles que no son originariamente pertenecientes a la Comunión anglicana, sino que fueron bautizados en la parroquia latina de la diócesis, comenzaron a asistir a la parroquia de Uso Anglicano al poco de su creación y ya forman parte de la parroquia; sus hijos han recibido allí los sacramentos desde el bautismo hasta el matrimonio, etc. Hay también grupos de fieles en estas parroquias que proceden no ya de la Iglesia católica o la Comunión anglicana sino de comunidades protestantes, evangélicas, luteranas o incluso que no profesaban ninguna religión y fueron recibidos en la Iglesia católica a través de la pastoral de estas parroquias o de algunas societies aprobadas por el obispo de la diócesis. ¿Puede considerarse a estos fieles como «originariamente pertenecientes a la Comunión anglicana» o puede entenderse que poseen al menos un cierto background anglicano para poder incorporarse al ordinariato? La respuesta, atendiendo al origen, al motivo y a los objetivos de la ley, creo que debe ser positiva.

La Constitución Apostólica tiene entre sus objetivos reconocer, mantener, proteger y asegurar que se conserven dentro de la Iglesia católica aquellas tra-

${ }^{23}$ Estas parroquias son parroquias personales y fueron creadas a través de la Pastoral Provision a partir de 1981 para acoger a grupos de fieles provenientes de la Iglesia Episcopal. Utilizaban para la liturgia The Book of Divine Worship, un libro litúrgico que contiene las oraciones de tradición Anglicana con la inclusión de las cuatro plegarias Eucarísticas principales del Misal Romano y la oración de las ofrendas. Según un estudio realizado en 2008, el número total de fieles de Uso Anglicano en Estados Unidos era de 1.957 en tres parroquias personales de Uso Anglicano y cinco societys o congregations (J. M. SHEEHAN, A new canonical configuration for the Pastoral Provision for former episcopalians in the United States of America?, Tesi di Dottorato discussa nella Facoltà di Diritto Canonico della Pontificia Università della Santa Croce, Roma 2009, 391). En marzo de 2012, la web de la Pastoral Provision (www.pastoralprovion.org) informaba de la existencia de siete parroquias personales de Uso anglicano, aunque en la práctica son tres parroquias, dos societys, una congregation y una mission. Muchas de estas parroquias han entrado a formar parte del Ordinariato de The Chair of Saint Peter. 
diciones y costumbres espirituales, pastorales y litúrgicas de la Comunión anglicana que sean en el fondo y en la forma parte de la Iglesia católica. Y precisamente esto último es lo que se hace en las parroquias y grupos de la Pastoral Provision desde hace tiempo. De hecho, están teniendo un papel fundamental en la implementación de AC en Estados Unidos. Aquellos fieles que son miembros de estas parroquias o grupos pero no son «originariamente pertenecientes a la Comunión anglicana» en la práctica conocen las tradiciones litúrgicas, espirituales y pastorales anglicanas y las viven ya dentro de la Iglesia católica. Es decir, han sido una anticipación de la vida de un ordinariato y son también una cierta garantía de que el ordinariato puede crecer $^{24}$. Por ejemplo, en la curia del ordinariato de The Chair of Saint Peter se considera que su asistencia frecuente a la parroquia ya es signo de cierta conexión orgánica con el anglicanismo y se les admite en el ordinariato. De hecho, para que este problema no vuelva a ocurrir en las parroquias de los ordinariatos, el papa Francisco aprobó el 31 de mayo de 2013 una modificación en las Normas Complementarias por la que una persona que ha sido bautizada en la Iglesia católica pero que no ha completado los sacramentos de iniciación cristiana y regresa a la fe y a la práctica de la Iglesia como resultado de la misión evangelizadora del ordinariato, puede ser admitida como miembro del ordinariato (art. $5 \$ 2 \mathrm{NC}$ ).

En este sentido, el 21 de marzo de 2017, la primera parroquia personal de la Pastoral Provisión, Our Lady of Atonement, fue transferida de la diócesis de San Antonio, al Ordinariato de TCSP. En este tiempo comenzarán el proceso de incorporación de los fieles uno a uno o por familias ${ }^{25}$.

\subsection{Fieles que reciben los sacramentos de iniciación en la jurisdicción del ordinariato $(A C I \$ 4)$}

La Constitución Apostólica prevé que también puedan formar parte del ordinariato aquellos «que reciben los sacramentos de iniciación en la jurisdicción del Ordinariato mismo» (AC I $\$ 4$ in fine). Las NC concretan que se refiere tanto a un fiel proveniente del anglicanismo (NC art. $5 \$ 1$ ) como a un

${ }^{24}$ Por comparación, cuando se erigió la Administración Personal de Campos se concedía el derecho de incorporación a aquellos fieles que pertenecían a la Unión San Juan María Vianney. Cfr. art. IX del Decreto de erección de la Administración Personal de Campos (AAS 94 [2002] 305308). L. LANDETE CASAS, La atención pastoral de los fieles tradicionalistas: garantías para su plena inserción en la communio ecclesiastica, Fidelium Iura 11 (2001) 169-192, 187.

25 www.ordinariate.net/news/becoming-one (acceso 27/3/2017). 
fiel que fue bautizado en la Iglesia católica pero que no ha completado los sacramentos de la iniciación y sucesivamente vuelve a la fe y a la práctica de la Iglesia por la actividad apostólica realizada en el Ordinariato (NC art. $5 \$ 2$ ).

Atendiendo a estos criterios, hay varios tipos de posibles miembros:

1. Fieles laicos, clérigos y miembros de institutos de vida consagrada o de sociedades de vida apostólica, pertenecientes a la Comunión anglicana que: a) son recibidos en la Iglesia católica; b) reciben alguno de los sacramentos de iniciación en la jurisdicción del ordinariato personal ${ }^{26}$; c) manifiestan su voluntad de incorporarse al ordinariato; y d) son admitidos.

2. Cualquier mayor de 14 años no bautizado que entre en la Iglesia católica a través del ordinariato personal, y manifiesta su voluntad de incorporarse a él.

3. Aquellos fieles que llegan a la fe católica a través de la actividad apostólica del Ordinariato y reciben en él alguno de los sacramentos de iniciación: bautismo, y si ya lo han recibido (en la Comunión anglicana o en la Iglesia católica), la confirmación o la Eucaristía o ambos.

4. Los recién nacidos hijos o familiares de un fiel del ordinariato bautizados en la jurisdicción del ordinariato o incluso fuera de esa jurisdicción ${ }^{27}$. Sus padres o tutores realizan en su nombre la manifestación de voluntad de incorporarse al ordinariato.

5. Mayores de 14 años que reciban la formación para acceder por primera vez al sacramento de la Eucaristía o reciben la Confirmación en la jurisdicción del ordinariato, manifiestan su voluntad de pertenecer a él y son aceptados por el ordinario.

Nada se señala en la ley sobre los menores de edad. En este sentido, el primer ordinario de The Chair of Saint Peter en una carta pastoral, que puede considerarse un reglamento, aclaraba algunos de estos aspectos. Efectivamente los menores se pueden incorporar al ordinariato cuando lo hacen sus

${ }^{26}$ En el caso de los ya bautizados se entiende que ocurrirá así cuando reciban el sacramento de la confirmación válidamente.

27 También el hijo de un miembro del ordinariato puede ser bautizado fuera de la jurisdicción del ordinariato, y posteriormente ser inscrito en el ordinariato a través de uno de sus padres o los dos, informando a la curia del ordinariato y enviando los datos necesarios. En la práctica, se está actuando así sobre todo en Estados Unidos y Canadá, en los casos de fieles del ordinariato que están lejos de una parroquia personal. 
padres, o sólo uno de ellos (se sobrentiende que con el consentimiento del otro). Pero siempre a través de una solicitud por escrito. En el Ordinariato de Our Lady of Walsingham se considera que pueden rellenar y firmar personalmente la petición los mayores de 8 años con el consentimiento de sus padres. Los menores de 8 únicamente con la firma de sus padres ${ }^{28}$. Es decir se está utilizando el uso de razón como medida. No es necesario que un menor ratifique su voluntad de pertenecer al ordinariato cuando cumple 14 años, se presume que lo desea salvo manifestación en contrario ${ }^{29}$. El menor sí puede cambiar de jurisdicción (suponiendo que la del ordinariato fuera exclusiva ${ }^{30}$ ) alcanzados los 14 años enviando una carta de renuncia al ordinariato. También en el caso de que uno de los padres pertenezca al ordinariato y otro a una Iglesia sui iuris puede elegir a partir de los 14 años. En esta cuestión, pueden servir de guía orientativa las normas codiciales sobre la adscripción a la Iglesia ritual sui iuris $^{31}$, pero sin olvidar que en el caso de los ordinariatos estamos ante una circunscripción personal no ante una Iglesia Ritual y por lo tanto no hay obligación de aplicar este tipo de normas. Puede el ordinario, con el tiempo en función de la experiencia a través de los estatutos particulares dar normas sobre la materia.

${ }^{28}$ Se puede ver el formulario en www.ordinariate.org.uk/cmsAdmin/uploads/application_enrollment.pdf (acceso 10/2/2016).

${ }^{29}$ Información recibida de la curia del Ordinariato de The Chair of Saint Peter.

${ }^{30}$ Más adelante tratamos de ello.

31 Si el bautizado es mayor de 14 años, en el momento del bautismo elige libremente la Iglesia sui iuris de pertenencia (CIC, c. $111 \$ 2$; CCEO, c. 30). Si el bautizando es menor de 14 años, se sigue este criterio: si los dos padres pertenecen a la Iglesia latina, los niños se adscriben a esta Iglesia. Si uno de los padres no pertenece a la Iglesia latina -y si los dos padres están de acuerdo- los niños pertenecen a la Iglesia latina. A falta de acuerdo, prevalece la Iglesia sui iuris del padre. El CCEO también establece el principio de que el bautizando menor de edad, pero mayor de 14 años elige libremente la Iglesia sui iuris de pertenencia (c. 30). Este canon es más completo en la descripción de las diferentes situaciones en las que un menor de 14 años puede ser bautizado, y no sigue los mismos criterios del CIC en esta materia, dando preferencia a la Iglesia sui iuris del padre (c. 29). En primer lugar, establece una distinción entre los niños nacidos del matrimonio entre católicos (o en el que uno de los cónyuges es católico) y los niños nacidos de otras uniones. En el primer caso, los hijos menores de 14 años siguen la Iglesia sui iuris del padre católico, salvo que los padres den su consentimiento para que el hijo siga la Iglesia sui iuris de la madre. Si solamente la madre es católica, entonces el niño será inscrito en la Iglesia sui iuris de ésta (c. 29 \$ CCEO). Estas normas también se aplican en los casos de adopción. Los casos especiales se regulan en el c. 29 \$2 CCEO: a) Los niños nacidos fuera del matrimonio se adscriben a la Iglesia de la madre. b) Los hijos de padres desconocidos son adscritos a la Iglesia de las personas a cuyo cargo están legalmente encomendadas. c) Los niños nacidos de padres no bautizados se adscriben a la Iglesia sui iuris de aquel que se ha comprometido a educarles en la Iglesia católica. Cfr. L. NAVArRo, Persone e soggetti nell diritto della Chiesa. Temi di diritto della persona, Edusc, Roma 2000, 54-55. 


\subsection{Los «miembros de una familia del ordinariato»}

Señala NC art. $5 \$ 1$ in fine: «de ordinario, quienes fueron previamente bautizados como católicos fuera del Ordinariato no pueden ser admitidos como miembros, a no ser que sean miembros de una familia que pertenezca al Ordinariato».

Aunque la ley señala que debe ser «miembro de una familia del Ordinariato» es éste un concepto un tanto vago. En la ley no queda determinado el grado de parentesco necesario. Para Díaz Moreno, el grado de parentesco permitido sería el de primer grado en línea recta (padres, hijos, nietos) y colateral en segundo (hermanos) ${ }^{32}$. Para Galles, al no quedar explicado se debe acudir al c. 1091 que aunque se refiere al matrimonio, puede servir como uno de los lugares paralelos a los que alude el c. 17. Así, «miembros de una familia» incluiría a todos los ascendientes y descendientes legítimos y naturales en línea recta de consanguinidad, y en línea colateral, hasta el cuarto grado inclusive $^{33}$.

Realmente creo que debe hacerse una interpretación amplia de este artículo y que debe entenderse que puede formar parte del ordinariato cualquier pariente en cualquier grado de consanguinidad o afinidad de un miembro del ordinariato que manifieste su voluntad de incorporarse y sea admitido por el ordinario. También se debe tener en cuenta en este apartado, como decíamos antes, a las personas que forman parte de las parroquias de Uso Anglicano de Estados Unidos pero no sean originariamente pertenecientes a la Comunión anglicana. Más aún teniendo en cuenta que la mente en la modificación de 2013 de las NC fue que el ordinariato participe activamente en la nueva evangelización $^{34}$.

32 «No se precisa qué grado de nexo familiar se exige, para que estos bautizados puedan pasar a formar parte de Ordinariato. Desde luego entendemos que comprende los denominados primeros grados de la línea recta (padres, hijos, nietos) y la colateral en segundo grado (hermanos)». J. M. Díaz Moreno, Constitución «Anglicanorum Coetibus» sobre la institución de Ordinariatos personales para los anglicanos que ingresan en la plena comunión con la Iglesia, Revista Española de Derecho Canónico 67 (168) 2010, 427, nota 36.

33 D. GALLES, Anglicanorum Coetibus, some canonical investigations on the recent apostolic constitution, The Jurist 71 (2011) 201-233, 214, nota 33.

${ }^{34}$ Así lo interpretaba el primer ordinario de The Chair of Saint Peter cuando se promulgó la modificación http://www.usordinariate.org/membership_norms_amended.html (acceso 10/2/2016). 


\section{Casos EXCEPCIONALES DE INCORPORACión}

Pienso que puede incorporarse al ordinariato de forma excepcional cualquier persona que estime conveniente la Santa Sede o el ordinario con su permiso y tal vez con la consulta al Consejo de Gobierno (aunque nada especifica la ley sobre esto). Creo que habría que distinguir dos tipos de casos excepcionales: Aquellos en los que es la persona quien solicita incorporarse al ordinariato y aquellos en los que no lo ha solicitado la persona, pero el ordinario o la Santa Sede podría juzgar que es conveniente que forme parte del ordinariato, por ejemplo por el oficio que desempeña.

Respecto al primer caso, en la práctica se están dando algunas peticiones. Por ejemplo, fieles que han sido bautizados en otras comuniones pero quieren entrar en el ordinariato y no tienen un background anglicano. Lo que suelen hacer es empezar a participar en la vida del ordinariato, ser recibidos en la Iglesia católica a través del ordinariato y posteriormente solicitar la incorporación.

¿Qué ocurre con aquellos fieles católicos latinos sin ningún familiar en un ordinariato que quisieran ser miembros de uno? En principio la normativa es restrictiva y no pueden ser recibidos, pero pienso que cabe una incorporación excepcional. Bastan las razones de conveniencia para el fiel en concreto y para el ordinariato.

La otra forma excepcional de incorporación se puede dar cuando no lo solicita el propio interesado sino que sea conveniente que haya fieles que pertenezcan al ordinariato pero no sean ellos quienes soliciten su incorporación y que ésta sea determinada bien por ley general (como en el caso de los ordinariatos militares) o por los Estatutos Particulares de un ordinariato. Pueden ser casos muy diversos; jueces del futuro tribunal del ordinariato, canciller, oficios técnicos de la curia, profesores de la casa de formación o del futuro seminario cuando sea posible erigirlo, de un colegio anejo a una parroquia, etc. Lógicamente no es necesario estar incorporado al ordinariato para desempeñar alguno de esos oficios o participar de su vida como ocurre en la práctica.

Un caso paradigmático ha sido el nombramiento por parte de la Santa Sede del segundo ordinario del Ordinariato de The Chair of Saint Peter. Se trata de un sacerdote católico que «técnicamente» no cumple ninguno de los requisitos que señala la ley, pues no fue anglicano, ni ministro anglicano, ni tiene ningún background anglicano. Fue bautizado en la Iglesia católica y siem- 
pre ha vivido y desarrollado su actividad pastoral en ella. Fue ordenado obispo en febrero de $2016^{35}$.

\section{LA CUESTIÓN DE LA PERTENENCIA DE LOS FIELES DEL ORDINARIATO A LA DIÓCESIS DONDE TIENEN EL DOMICILIO}

Estudiada la cuestión sobre quiénes pueden forman parte de un ordinariato vayamos a otra de las cuestiones importantes: si los fieles de un ordinariato personal pertenecen también a la diócesis donde tienen el domicilio.

Es éste uno de los puntos que ha suscitado mayor debate en la doctrina. De hecho, para Mons. Burnham -uno de los tres primeros obispos anglicanos en ser recibidos en la Iglesia católica a través del ordinariato de OLW, asistente del primer ordinario y miembro del primer consejo de Gobierno de OLW- es una cuestión aún por decidir ${ }^{36}$. Para numerosos autores la percepción sobre si los fieles de un ordinariato pertenecen o no a la diócesis donde tienen el domicilio depende de la consideración que se haga de la jurisdicción del ordinario personal; si estamos ante una jurisdicción exclusiva o cumulativa con la del obispo diocesano.

\subsection{Posturas y argumentos que niegan la pertenencia de los fieles de un ordinariato personal a la diócesis donde tienen el domicilio}

Algunos autores ${ }^{37}$ señalan que la Constitución Apostólica prevé que los fieles de los ordinariatos personales formen parte del ordinariato personal pero no

35 Se trata de Mons. Lopes que desde la erección de los ordinariatos personales ha trabajado en la Santa Sede en la Comisión Anglicanae Traditiones, que ha seguido todo el proceso de erección de los ordinariatos y la aprobación del nuevo Misal. Es un gran conocedor de las tradiciones anglicanas, litúrgicas, pastorales y espirituales (más información sobre Mons. Lopes, su ordenación y sus tareas en www.ordinariate.net/bishop-lopes [acceso 25/3/2017]).

36 A. Burnham, The Personal Ordinariate of Our Lady of Walsingham, Pastoral Review, vol. 7, Issue 5 (2011) 2-27, 24-25.

37 Así lo señala G. Ghirlanda estableciendo una comparación con lo que ocurría en la Pastoral Provision: «mentre la Pastoral Provision prevedeva che i fedeli provenienti dall'Anglicanesimo appartenessero alla diocesi in cui avessero il domicilio, pur essendo oggetto di una particolare cura pastorale da parte del Vescovo diocesano, la Costituzione Apostolica Anglicanorum Coetibus prevede che fanno parte dell'Ordinariato Personale, non della diocesi in cui stabiliscono il loro domicilio». Cfr. G. GHIRLANDA, Il significato della costituzione apostolica Anglicanorum Coetibus..., cit., 388; IDEM, Una normativa essenziale per una struttura canonica flessibile, L'Osservatore Romano 9-IX-2009, 6-7; IDEM, La Costituzione Apostòlica Anglicanorum Coetibus..., cit., 413. En la misma línea A. Jeremy, Apostolic Constitution Anglicanorum Coetibus and personal ordinariate of Our 
de la diócesis en la que establecen su domicilio ya que la potestad del ordinario personal no es cumulativa con la del obispo diocesano, pues si no, se habría recurrido a la misma terminología utilizada en Spirituali Militum Curae y en Animarum bonum, documentos en la que aquélla -en otros puntos- se inspira ${ }^{38}$. Otro argumento que se aporta para la no pertenencia de los fieles a la diócesis donde tienen el domicilio es la justa autonomía que se quiere que tenga un ordinariato personal para fieles provenientes del anglicanismo y se evite una asimilación sin más en la diócesis y una pérdida de la riqueza de las tradiciones anglicanas ${ }^{39}$.

El hecho es que en la práctica -por la novedad de la figura, por el silencio de la norma y por las cuestiones que deben solucionarse en el día a día- por ejemplo, en el ordinariato de The Chair of Saint Peter en estos primeros años y hasta que haya una declaración formal de la autoridad -que se basará, me parece, en la experiencia recogida- se actúa con aquellos que desean solicitar la incorporación, como si se tratase de una jurisdicción exclusiva ${ }^{40}$. Por ejemplo, cuando un fiel (o una familia) que no cumple los requisitos previstos en AC solicita incorporarse al ordinariato ${ }^{41}$, antes de admitirlo, desde el ordinariato se consulta al obispo de la diócesis que debe dar su consentimiento por escrito. $\mathrm{Si}$ el obispo no lo concede, no se permite que el fiel forme parte del ordinariato.

Aparte de este hecho, para los autores que piensan que los fieles de un ordinariato no forman parte de la diócesis, hay algunos artículos en la ley que sugieren esta interpretación. Son el art. $5 \$ 3$ de las NC, y los nn. 5 y 10 de los tres primeros decretos de erección que estudiamos a continuación.

\subsection{El art. $5 \$ 3$ de las $N C$ y los nn. 5 y 10 de los tres primeros Decretos de Erección}

$\mathrm{El}$ art. $5 \$ 3$ de las $\mathrm{NC}$ establece que «Los fieles laicos y los miembros de institutos de vida consagrada y de sociedades de vida apostólica, cuando cola-

Lady of Walsingham..., cit., 427; y N. DoE, The Apostolic Constitution Anglicanorum Coetibus: An Anglican Furidical Perspective..., cit., 310.

38 G. Ghirlanda, La Costituzione Apostòlica Anglicanorum Coetibus..., cit., 410 y 394.

39 G. GHIRLANDA, Una normativa essenziale per una struttura canonica flessibile, L'Osservatore Romano 9-IX-2009, 6-7.

40 Entrevista con Margaret Chalmers, canciller del ordinariato de TCSP del 2012 al 2015. Vía e-mail 23-III-2012.

${ }^{41}$ La mayor parte de los casos son fieles católicos sin pasado anglicano que llevan años acudiendo a una parroquia de Uso Anglicano de la Pastoral Provision, que son parroquias que pertenecen a la diócesis. 
boran en actividades pastorales o caritativas, diocesanas o parroquiales, dependen del obispo diocesano o del párroco del lugar, por lo que en este caso la potestad de estos últimos se ejerce de modo conjunto con la del Ordinario y la del párroco del Ordinariato ${ }^{42} \gg$.

Para algunos autores ${ }^{43}$, con esta expresión, se da a entender que en los demás casos, los fieles no dependerían del Obispo diocesano. Sin embargo pienso que aunque pueda ser así, no parece que la ley quiera instaurar un régimen de exención general de los fieles ya que hay otras materias no especificadas en la ley en las que un fiel del ordinariato, por derecho común dependerá del obispo diocesano ${ }^{44}$.

Otros textos legales que pueden sugerir que los fieles de un ordinariato personal no forman parte de la diócesis los encontramos en los nn. 5 y 10 de los Decretos de erección de los tres primeros ordinariatos:

El n. 5 establece que:

«Para que un clérigo no incardinado en el Ordinariato personal de [...] pueda asistir a un matrimonio entre fieles pertenecientes al Ordinariato, debe recibir la facultad del Ordinario o del pastor de la parroquia personal a la que pertenecen los fieles».

Para Viana el hecho de que la ley prevea la necesidad de esta delegación no tendría sentido si la potestad fuese cumulativa ${ }^{45}$. Para Read, también la redacción de este n. 5 hace pensar que estamos ante una jurisdicción exclusiva. Esta disposición es paralela -señala- a la que se aplica a los católicos ucranianos y a otro tipo de católicos orientales en territorio latino ${ }^{46}$. Pero de hecho, como veremos más adelante, a pesar de requerirse esta delegación, en virtud

${ }^{42} \mathrm{NC}$ art. $5 \$ 2:$ : Lay faithful and members of Institutes of Consecrated Life and Societies of Apostolic Life, when they collaborate in pastoral or charitable activities, whether diocesan or parochial, are subject to the Diocesan Bishop or to the pastor of the place; in which case the power of the Diocesan Bishop or pastor is exercised jointly with that of the Ordinary and the pastor of the Ordinariate».

43 E. BAURA, Los ordinariatos personales para antiguos anglicanos. Aspectos canónicos de la respuesta a los grupos de anglicanos que quieren incorporarse a la Iglesia católica..., cit., 250-251. En la misma línea, A. Viana, Ordinariatos y Prelaturas personales. Aspectos de un diálogo doctrinal..., cit., 514, nota 61.

${ }^{44}$ Trato sobre ello al final del artículo en el apartado Relaciones jurídicas del fiel del ordinariato con la diócesis.

45 Así lo señala A. Viana, Ordinariatos y Prelaturas personales. Aspectos de un diálogo doctrinal..., cit., 515.

${ }^{46}$ G. READ, Anglicanorum Coetibus - a year of developments. Coment on de Decre of Erection of the Personal Ordinariate of Our Lady of Walsingham (pro manuscripto). Publicado en Newsletter n. 165 de la Canon Law Society of Great Britain and Ireland, March 2011, 8-16. 
de los cc. 1109 y 1110 un fiel del ordinariato en la práctica podría contraer matrimonio válidamente ante el párroco territorial o el ordinario del lugar.

Por último, que los fieles no pertenecen a las dos jurisdicciones podría desprenderse del n. 10 de los tres primeros decretos de erección donde se prevé que:

«(...). Si un fiel desea abandonar el Ordinariato, debe dar a conocer esta decisión a su propio Ordinario. Así se convierte automáticamente en miembro de la diócesis donde reside. En ese caso, el ordinario debe asegurar que el obispo diocesano es informado $(. . .)^{47} \gg$.

Del texto de este $\mathrm{n} .10$ se podría deducir que se da por supuesto ${ }^{48}$ que el fiel «mientras pertenezca al ordinariato no sería miembro de la diócesis ${ }^{49} \gg$. Sin embargo, pienso que esto es también interpretable a la inversa: si el fiel no forma parte de la diócesis, si abandona el ordinariato no puede pasar automáticamente a la diócesis sin ningún procedimiento, con la simple información del ordinario al obispo. Si el ordinariato personal es una jurisdicción exclusiva creo que tendría que haber entonces un proceso de paso a la diócesis, no mero automatismo. Me parece que es aclaratorio lo que señala Arrieta: «en realidad no se convierte en fiel de la diócesis en el sentido de que antes no formase parte (...). Lo que realmente ocurre es [que] desde ese momento cesa, respecto a su persona, todo límite a la jurisdicción del obispo diocesano que las normas especiales hubiesen podido establecer ${ }^{50} \gg$. Me parece que es a esos efectos la información entre ordinarios que señala este n. 10.

En principio, cualquier católico que tiene su domicilio o cuasidomicilio en el territorio de una diócesis es miembro de esa diócesis (cc. 107, $372 \$ 1$ ).

47 Art. 10 DEPOOLW, DEPOTCSP, DEPOOLSC: «If a member of the faithful moves permanently into a place where another Personal Ordinariate has been erected, he is able, on his own request, to be received into it. The new Ordinary is bound to inform the original Personal Ordinariate of the reception. If a member of the faithful wishes to leave the Ordinariate, he must make such a decision known to his own Ordinary. He automatically becomes a member of the Diocese where he resides. In this case, the Ordinary will ensure that the Diocesan Bishop is informed».

48 E. BAURA, Los decretos de erección de los Ordinariatos Personales para antiguos fieles anglicanos, Revista General de Derecho Canónico y Derecho Eclesiástico del Estado 28 (2012), en www.iustel. com, 10-11.

49 A. Viana, Ordinariatos y Prelaturas personales. Aspectos de un diálogo doctrinal..., cit., 515.

50 J. I. ARrIETA, Sulla natura giuridica degli Ordinariati personali, en AA.Vv., Sufficit Gratia Tua. Miscellanea in onore del Card. Angelo Scola per il suo $70^{\circ}$ compleanno, Marcianum Press, Venezia 2012, $67-79,75$. 
No es exento si no lo establece explícitamente una norma del derecho o un acto de la autoridad competente, cosa que de momento no se ha producido para los ordinariatos personales. Otra cosa es que sea también destinatario de leyes particulares o especiales que establecen legítimamente otros criterios prevalentes respecto al derecho común para determinar quién y a qué efectos y con qué extensión es la autoridad eclesiástica que puede actuar en las diversas materias sobre él. $\mathrm{O}$ que efectivamente existan algunas materias en las que exclusivamente depende del ordinario. Esto sucede siempre que se erige una circunscripción personal en un ámbito en el que ya se ejerce una jurisdicción delimitada territorialmente. El derecho establece en esos casos, además de los criterios de determinación de los fieles de la circunscripción (que nunca puede ser exclusiva en sentido absoluto, porque pertenecen a la Iglesia; y tampoco en sentido relativo, salvo en casos de exención explícita) las reglas jurídicas de ejercicio de la potestad por los distintos pastores. En algunos casos, como puede ser el del ordinariato personal, la regla puede ser la exclusividad de uno de ellos, pero pienso que eso no significa que se eliminen los vínculos del fiel con la diócesis de su domicilio o cuasidomicilio: simplemente es una regla jurídica que se aplica en determinados casos para efectos jurídicos (competencia, validez o licitud de actos, responsabilidad, etc.).

\subsection{Posturas y argumentos a favor de la pertenencia de los fieles de un ordinariato personal a la diócesis donde tienen el domicilio}

Como señala Miras, creo que si se opta por hablar en términos de pertenencia, habría que distinguir entre «una dimensión primera y radical, o un momento primario de la pertenencia que traduce canónicamente toda la sustancia ontológica de la condición de fiel y del ser de la Iglesia; y un momento secundario, complementario y funcional respecto al anterior, en el que esa pertenencia radical se determina en otras pertenencias que la presuponen y están a su servicio $^{51} \gg$. Por eso, pienso que un fiel puede pertenecer simultáneamente a varias circunscripciones eclesiásticas con pertenencias de análogo o diverso alcance canónico merced a distintos criterios ${ }^{52}$. Así, por ejemplo, un fiel que proviene

\footnotetext{
${ }^{51}$ J. Miras, La delimitación de las comunidades de fieles en la organización pastoral de la Iglesia. Observaciones sobre el sentido de los criterios objetivos que usa el derecho canónico, Fidelium Iura 11 (2001) 41-63, 56 .

${ }^{52}$ Ibid., 57.
} 
del anglicanismo y forma parte de un ordinariato personal, si es militar, pertenece también al Ordinariato militar por razón de su condición profesional; además, mediante la vía convencional prevista en el c. 296, también podría pertenecer a una prelatura personal. Por el domicilio o cuasidomicilio (cc. 107 y 372 $\$ 1$ ) forma parte también de una diócesis. «Cada una de esas pertenencias da lugar a derechos, deberes, facultades, competencias y responsabilidades -pastorales y del sujeto-, que se articulan, según las normas aplicables en cada caso, mediante regímenes jurídicos diversos: en algunos casos le seguirá su familia y en otros no; en unas materias habrá exclusividad, en otras concurso cumulativo o mixto de jurisdicciones; para ciertos actos el sujeto deberá acudir a un determinado ámbito pastoral, para otros tendrá la facultad de elegir ${ }^{53} \gg$.

En esta línea, varios de los autores que han comentado AC sí piensan que los fieles de un ordinariato personal pertenecen a la diócesis donde tienen el domicilio $^{54}$. Si se hubiesen querido cambiar estas normas de coordinación la ley debería haberlo dicho expresamente ${ }^{55}$. Estos autores coinciden en que al ordinariato personal le es aplicable lo que declaran los nn. 9, 10 y 16 de la Carta Communionis Notio ${ }^{56}$.

En virtud del n. 9 de esta Carta no se concibe en la eclesiología católica la sola pertenencia a la Iglesia Universal, porque esta categoría es inmanente a aquélla de Iglesia Particular, pues se trata de dos conceptos inseparables uno del otro. Por ello, para Arrieta, «los fieles del ordinariato, con la profesión de fe, se incorporan a la Iglesia particular del domicilio y son confiados a ese pastor propio, mientras que con la solicitud voluntaria y con la inscripción en el registro especial, quedan incorporados también al ordinariato personal y confiados a la especial cura pastoral del ordinario personal ${ }^{57} \gg$.

53 J. MiRAs, La delimitación de las comunidades de fieles en la organización pastoral de la Iglesia. Observaciones sobre el sentido de los criterios objetivos que usa el derecho canónico, Fidelium Iura 11 (2001) 41-63, 58.

${ }^{54}$ J. I. ARRIETA, Gli Ordinariati personali..., cit., 169; J. HuELs, Canonical comments on Anglicanorum Coetibus, Worship, Edited by Benedictines of St. John's Abbey (MN. USA) 84 (2010) 237-253, 242; J. Renken, The Personal Ordinariate of the Chair of St. Peter, Studia Canonica 46 (2012) 5$50,28-29$.

55 «La única conclusión que parece proceder de esto, es que la norma que comentamos, no tenga por objeto modificar la certeza jurídica de las normas comunes del derecho canónico que determinan el poder de los pastores involucrados, de lo contrario, se habría requerido una declaración explícita de la ley, que sin embargo, no se ha querido hacer». J. I. ARRIETA, Gli Ordinariati personali..., cit., 169 (traducción propia).

56 J. I. ARriETA, Gli Ordinariati personali..., cit., 166 y ss.

57 J. I. ARRIETA, Gli Ordinariati personali..., cit., 166-167. 
Efectivamente como explica el n. 10 de Communionis Notio, la incorporación a la Iglesia de un bautizado se produce «en» una Iglesia Particular, pues no existe la incorporación exclusiva y directamente en la Iglesia Universal.

Pienso que abunda en este argumento el iter exigido por la ley para incorporarse a un ordinariato personal, que requiere una manifestación de voluntad realizada por escrito, que es un acto distinto formalmente y en el tiempo -aunque se pueda hacer en la misma ceremonia- de la adhesión a la Iglesia católica a través de la profesión de fe o en su caso, del bautismo. Hay fieles que pueden ser bautizados en una parroquia del ordinariato, pero no deseen pertenecer a él. Es decir, no por el hecho de realizar la profesión de fe o por recibir el bautismo en la jurisdicción del ordinariato, la incorporación es automática. De hecho hay también fieles del ordinariato que han sido recibidos en la Iglesia católica en una parroquia de la diócesis, y posteriormente han manifestado su voluntad de pertenecer al ordinariato.

En segundo lugar, siguiendo el n. 16 de Communionis Notio, además de las Iglesias Particulares, existen circunscripciones para servicios pastorales específicos que pertenecen eclesiológicamente a la lógica de la Iglesia Universal. $\ll$ A este tipo de estructuras pertenecen las circunscripciones eclesiásticas personales, y concretamente, también los ordinariatos personales ${ }^{58} \gg$. Los miembros de estas circunscripciones -señala Communionis Notio 16- «son también miembros de las Iglesias particulares donde viven y trabajan».

\subsection{Importancia del c. 107}

En función del c. 107 aquellos que pertenecen a una parroquia personal del ordinariato también pertenecerían ipso iure a la parroquia territorial y tienen derecho a los sacramentos y a la atención pastoral en ambas parroquias, aunque en la práctica puedan ejercitar ese derecho en la que consideren su propia parroquia ${ }^{59}$. En este sentido, el Ministry Manual ${ }^{60}$ del Ordinariato de The Chair of Saint Peter en un breve excursus previo, así lo da a entender: «El

${ }^{58}$ J. I. ARRIETA, Gli Ordinariati personali..., cit., 160.

59 En la misma línea, J. Huels, Canonical comments on Anglicanorum Coetibus, Worship, Edited by Benedictines of St. John's Abbey (MN. USA) 84 (2010) 237-253, 242 y 249; IDEM, Anglicanorum Coetibus; Text and Commentary..., cit., 398.

${ }^{60}$ El Ministry Manual es un reglamento interno para uso del ordinariato. Fue aprobado en noviembre de 2012 por el ordinario con el consentimiento del Consejo de Gobierno como prevén las Normas Complementarias. 
Derecho canónico no contempla la necesidad de registrarse en la parroquia. Se entiende que la gente acudirá ya sea a la parroquia del territorio donde reside o a la parroquia personal propia. En algunos casos, las personas eligen registrarse como miembros de una parroquia distinta de la parroquia territorial en la que viven ${ }^{61} \gg$. También en el Ministry Manual se exige al párroco personal que solicite la delegación por escrito al párroco territorial para administrar los sacramentos del bautismo, confirmación y matrimonio en parroquias del ordinariato a fieles que no formen parte de él ${ }^{62}$. Pero no se señala nada para el caso contrario, por lo que se puede entender que los fieles del ordinariato lo son también de la diócesis donde tienen el domicilio. Por ejemplo, en el caso del grupo de Escocia del ordinariato de Our Lady of Walsingham, en la práctica, al tener dificultades para reunirse por las distancias o falta de templos, la mayoría de los fieles asisten a su parroquia territorial y se reúnen una vez al mes o cuando es posible para celebrar la Eucaristía según el nuevo Misal aprobado para los ordinariatos personales. De hecho reciben una esmerada atención de los párrocos locales y algunos obispos diocesanos ${ }^{63}$. $\mathrm{O}$ por ejemplo, en el Ordinariato de The Chair of Saint Peter, a aquellos fieles episcopalianos que desean ser recibidos en la Iglesia católica y no pueden prepararse en una parroquia del ordinariato o con un grupo de éste, se les pide que lo hagan a través de una parroquia de la diócesis ${ }^{64}$.

${ }^{61}$ Personal Ordinariate of the Chair of St. Peter, Manual ministry, Abridge Ministry Handbook (pro manuscripto), 7. La traducción es mía.

${ }^{62} \ll$ For Ordinariate parishes, the Pastor has authority over the members of his parish only, and he should be particularly sensitive to avoid encroaching on the rights and obligations of pastors of the diocesan territorial parishes. If a person who regularly attends but is not a member of an Ordinariate parish, wants to receive sacramental or pastoral ministry (e.g., baptism, confirmation, marriage, Christian funeral) the Ordinariate pastor must request and receive delegation in writing from the person's territorial pastor, and the record of the reception of the sacrament must be sent to the person's territorial parish to be recorded. Parish affiliation, or lack of it, is not to be used as a reason to deny sacramental or pastoral ministry unless the territorial pastor refuses delegation. However, where verification of records or other requirements warrant, Sacraments may be delayed». Personal Ordinariate of the Chair of ST. Peter, Manual ministry, Abridge Ministry Handbook (pro manuscripto), 7.

${ }^{63}$ El número de agosto de 2015 de la Revista The Portal, la revista oficial del ordinariato de OLW está dedicado íntegramente al grupo de Escocia y explica todas estas cuestiones (disponible en /www.portalmag.co.uk/portal/portal.pdf [último acceso 20/2/2016]).

${ }^{64}$ «If there is an Ordinariate community within a reasonable distance from you, we may suggest that you join them to do your preparation to come into the Church. If not, we will ask you to attend your local Latin Catholic Church and come into the Church through their RCIA program. Upon accepting your request, we will try to assign you to the care of the closest Ordinariate community, though this may take some time for us to get this organized» (Pastoral Letter, $\$ 12$ ). 
Como hemos visto, el legislador no ha declarado expresamente la jurisdicción exclusiva del ordinario personal sobre los fieles del ordinariato. Pero aunque la declarara, pienso que eso tampoco afectaría a la pertenencia del fiel a la diócesis, «sino a los actos concretos del ordinario y de otros ordinarios ${ }^{65} \gg$. En el caso de los ordinariatos personales esos ámbitos serían el sacramento del matrimonio, el sacramento del orden y el foro judicial.

\section{4. ÁMBITOS DE CONCURRENCIA DE JURISDICIONES}

\subsection{Sacramento del Matrimonio}

Sobre la facultad de asistir al matrimonio de un fiel del ordinariato, surgen algunas dudas. El ordinario y el párroco de una parroquia personal del ordinariato tienen la facultad de asistir al matrimonio en el que al menos uno de los contrayentes pertenece a la parroquia personal del ordinariato (c. 1108). Si otro presbítero -incardinado en el ordinariato o no- asiste al matrimonio, en principio debe recibir la delegación del ordinario personal o del párroco. En este sentido, el n. 5 de los tres primeros decretos de erección, establece que:

«Para que un clérigo no incardinado en el ordinariato personal de [...] pueda administrar un matrimonio entre fieles pertenecientes al ordinariato, debe recibir la facultad del Ordinario o del pastor de la parroquia personal a la que pertenecen los fieles ${ }^{66}{ } \gg$.

Pienso que esta disposición necesitaría algunas aclaraciones.

En primer lugar, llama la atención que la necesidad de esta facultad se refiera sólo al clero no incardinado en el ordinariato, como si se dedujese que cualquier clérigo incardinado en el ordinariato de que se trate, por el hecho de estarlo, tuviese las facultades de párroco para todos los fieles del ordina-

\footnotetext{
${ }^{65}$ Así me parece que lo señala Renken cuando dice que: «El ordinario y el obispo diocesano no tienen jurisdicción cumulativa sobre los fieles del ordinariato personal. Cada uno tiene jurisdicción en ámbitos distintos, complementarios y paralelos, pero no competencia en las mismas materias. Tal vez puedan considerarse las dos jurisdicciones como concurrentes, pero no superpuestas, sino cada una ejercida de manera cooperativa y coordinada para la correcta atención pastoral de los fieles del ordinariato personal». J. Renken, The Personal Ordinariate of the Chair of St. Peter, Studia Canonica 46 (2012), 5-50, 28-29.

${ }^{66}$ El original inglés señala «For a cleric not incardinated in the Personal Ordinariate of (...) to assist at a marriage of the faithful belonging to the Ordinariate, he must receive the faculty from the Ordinary or the pastor of the personal parish to which the faithful belong», N. 5 DEOLW y DETCSP.
} 
riato $^{67}$. No parece que por estar incardinado en el ordinariato, cualquier clérigo puede asistir válidamente al matrimonio de un fiel del ordinariato pues es necesaria la delegación del párroco personal o del ordinario personal ${ }^{68}$ (c. 1111). De hecho, para algunos autores la delegación del párroco personal es necesaria «para la validez» ${ }^{69}$.

Sin embargo, creo que este criterio no sería aplicable al ordinario o párroco local (sí para otro clérigo ${ }^{70}$ ). Debemos tener en cuenta los cc. 1109 y 1110. Éstos señalan que el ordinario del lugar y el párroco territorial en virtud del oficio asisten válidamente dentro de su jurisdicción a los matrimonios de los súbditos y también de los que no son súbditos, con tal de que uno de ellos sea de rito latino. Teniendo en cuenta que los fieles del ordinariato son de rito latino podemos entender que el párroco territorial y el ordinario del lugar asisten válidamente tanto al matrimonio en el que uno de los fieles es súbdito suyo y el otro fiel del ordinariato, como al matrimonio de dos fieles

${ }^{67}$ E. BAURA, Los decretos de erección de los Ordinariatos Personales para antiguos fieles anglicanos..., cit., 13.

${ }^{68}$ Así sucede también en los ordinariatos militares. Un clérigo incardinado en el ordinariato militar asiste válidamente al matrimonio de un fiel del ordinariato militar no siempre, sino cuando éste se encuentra bajo su jurisdicción: en la parroquia o en territorio militar. Si no, es necesaria la delegación del ordinario militar. Para las prelaturas personales la competencia en materia matrimonial dependerá de que la celebración del matrimonio sea competencia del prelado o no y venga señalada en los estatutos. En el caso de la Prelatura Personal de la Santa Cruz y Opus Dei, «il diritto particolare non include direttamente la celebrazione del matrimonio fra la missione pastorale affidata dal Romano Pontefice alla prelatura dell'Opus Dei. Di fatto, le autorità della prelatura sostengono che sia seguita, in queste cause, la giurisdizione delle circoscrizioni territoriali (o anche personali, delle chiese rituali e particolari di tale natura o degli ordinariati militari, qualora il fedele della prelatura vi faccia parte) alle quali appartengono i fedeli dell'Opus Dei, senza che detta appartenenza venga a mancare per il fatto della loro incorporazione alla prelatura. Cfr. cost. ap. Ut sit, nn. 1, 3; Codex Iuris Particularis Operis Dei, nn. 1, 2 \$1, 11, 125, 171-180; Declaración Praelaturae personales, nn. 2, b), 3, a), 4, a) e c); Decreto di costituzione del Tribunale, n. 1». J. LlOBELL, I tribunali delle circoscrizioni personali latine, Il diritto ecclesiastico 113 (2002) 147-176.

${ }^{69}$ Señala Ghirlanda: «Per quello che riguarda l'assistenza a i matrimoni, hanno la facoltá ordinaria di assistere ai matrimoni dei fedeli dell'Ordinariato l'Ordinario e i parroci dell'Ordinariato stesso o qualsiasi sacerdote o diacono da loro delegati. Quindi se tali fedeli desiderano celebrare il matrimonio nella parrocchia del territorio in cui hanno il domicilio l'Ordinario o il parroco dell'Ordinariato, per la validitá della celebrazione, debbono delegare la facoltá di assistere a tale matrimonio. Inoltre, si deve tener conto del c. 1110: "L'ordinario e il parroco personali, in forza dell'ufficio assistono validamente saltanto al matrimonio di coloro di cui almeno un contraente sia suddito nell'ambito della sua giurisdizione"»(G. GHIRLANDA, La costituzione Apostólica Anglicanorum Coetibus..., cit., nota 63). Por contra señala Baura que el n. 5 de los dos primeros Decretos no señala «ad validitatem» (E. BAURA, Los decretos de erección de los Ordinariatos Personales para antiguos fieles anglicanos..., cit., 13).

${ }^{70}$ Clérigo de la misma diócesis pero que no es el propio del fiel, un clérigo de otra diócesis, de otra estructura jurisdiccional (otro ordinariato personal, un ordinariato militar, una prelatura personal), o de un IVC o SVA. 
del ordinariato si éstos se encuentran en su territorio mientras no se dicte una norma contraria. Como señala Baura, «teniendo en cuenta que las leyes irritantes han de ser interpretadas estrictamente -pues se considera que son limitativas del libre ejercicio de los derechos (c. 18)- habría que concluir que los fieles del ordinariato personal podrían contraer válidamente matrimonio en la parroquia territorial, sin necesidad de ulteriores requisitos ${ }^{71} \gg$. Por ello, pienso que un fiel del ordinariato puede elegir entre un clérigo del ordinariato o el párroco o el ordinario del lugar para asistir a su matrimonio ${ }^{72}$, ya que aunque se establezca esa necesidad de una delegación «el decreto de erección dado por la CDF no puede derogar al Código ${ }^{73} \gg$.

De todas formas ha de tenerse también en cuenta el Ritual del Matrimonio aprobado para los ordinariatos personales.

\subsection{El n. 3 del Ritual de Matrimonio aprobado para los ordinariatos}

El 22 de junio de 2012 fue promulgado por la Santa Sede el Ritual de matrimonio para los ordinariatos personales con el título The Order for the Cele-

${ }^{71}$ Cfr. E. BAURA, Los ordinariatos personales para antiguos anglicanos. Aspectos canónicos de la respuesta a los grupos de anglicanos que quieren incorporarse a la Iglesia católica..., cit., 262. A esta argumentación -señala el mismo autor- se podría objetar que el c. 829 \$ 1 CCEO, paralelo al c. 1109 latino, reconoce la facultad de asistir al matrimonio al Jerarca del lugar y al párroco territorial, con tal de que uno de los dos pertenezca a la misma Iglesia sui iuris (no ya a la misma tradición ritual ni en general a un rito oriental). Si se aplicase el mismo criterio al ámbito latino y se considerase que los ordinariatos para antiguos anglicanos forman una Iglesia sui iuris (de tradición latina) o son una jurisdicción exclusiva, efectivamente habría que concluir que los ordinarios locales y los párrocos territoriales no asisten válidamente a los fieles de los ordinariatos. Sin embargo, teniendo en cuenta que los ordinariatos personales no han sido declarados Iglesia sui iuris, que no está claro que posean jurisdicción exclusiva y que la norma oriental no es directamente aplicable al ámbito latino. Entiendo que entonces para Baura no se aplicaría al c. 829 CCEO la interpretación auténtica del PCTL que establece que se debe entender que la Iglesia Latina está implícitamente incluida cada vez que el CCEO utiliza expresamente el término Iglesia sui iuris en el contexto de relaciones jurídicas intereclesiales católicas (cfr. PONTIFICIO CONSEjO PARA LA Interpretación de los TeXtos Legislativos, Nota explicativa quo ad c. 1 CCEO, Communicationes 43 [2011] 315-316).

${ }^{72}$ En contra señala Read, que precisamente el n. 5 de los dos primeros decretos de erección hace deducir que estamos ante una jurisdicción exclusiva ya que para el matrimonio de dos fieles en el que ambos pertenecen al ordinariato, es necesaria la delegación del párroco o del ordinario (G. READ, Anglicanorum Coetibus - a year of developments. Coment on the Decree of Erection of the Personal Ordinariate of Our Lady of Walsingham, pro manuscripto, 6, publicado posteriormente en Newsletter n. 165 de la Canon Law Society of Great Britain and Ireland, March 2011, 8-16).

73 Cfr. E. BAURA, Los ordinariatos personales para antiguos anglicanos. Aspectos canónicos de la respuesta a los grupos de anglicanos que quieren incorporarse a la Iglesia católica..., cit., 262. 
bration of Holy Matrimony ${ }^{74}$. Según se establece en el n. 2, «su uso queda restringido al clero y a los fieles que pertenecen a alguno de los ordinariatos personales erigidos bajo la Constitución Apostólica Anglicanorum Coetibus». En el n. 3 se establece que:

«En casos de necesidad pastoral o en ausencia de un sacerdote o diácono incardinado en un ordinariato, cualquier sacerdote o diácono incardinado en una diócesis o en un Instituto de Vida Consagrada o Sociedad de Vida Apostólica puede presidir el rito del Matrimonio según The Order for the Celebration of Holy Matrimony para los miembros de un ordinariato que lo soliciten ${ }^{75} \gg$.

En este n. 3 se hace una remisión en nota al pie al art. $6 \$ 2$ de las NC que excluye como candidatos al sacerdocio en los ordinariatos a aquellos ministros anglicanos que antes hubiesen sido sacerdotes católicos y a los clérigos anglicanos que están en situaciones matrimoniales irregulares ${ }^{76}$. Puede tratarse de un error ${ }^{77} \mathrm{o}$ de un recordatorio expreso a que en estos casos de necesidad pastoral no se debe acudir a este tipo de ministros. Pero, volvamos al contenido del texto.

Pienso más bien que esta disposición del n. 3 es una disposición litúrgica y que quiere decir que cualquier diácono o sacerdote católico que celebre líci-

${ }^{74}$ Disponible en www.ordinariate.net/documents/resources/AC_Marriage_Rite.pdf (acceso 10/9/2016).

75 N. 3: «In cases of pastoral necessity or in the absence of a priest or deacon incardinated in an Ordinariate, any priest or deacon incardinated in a Diocese or in an Institute of Consecrated Life or Society of Apostolic Life may preside over the rite of Marriage according to The Order for the Celebration of Holy Matrimony for members of the Ordinariate who request it» (cfr. The Order for the Celebration of Holy Matrimony for use by the Ordinariates erected under the auspices of the Apostolic Constitution Anglicanorum Coetibus, 2).

${ }^{76} \mathrm{NC}$ art. $6 \$ 2$ «Quienes habían sido ordenados en la Iglesia católica y posteriormente se habían adherido a la Comunión anglicana, no pueden ser admitidos al ejercicio del ministerio sagrado en el ordinariato. Los clérigos anglicanos que están en situaciones matrimoniales irregulares no pueden ser admitidos a las sagradas órdenes en el ordinariato».

$77 \mathrm{Si}$ se tratase de un error, la referencia correcta supongo que sería al art. $9 \$ 2$ de las NC que señala que: «Donde y cuando se considere oportuno, los clérigos incardinados en una diócesis o en un instituto de vida consagrada o en una sociedad de vida apostólica, con el consentimiento escrito respectivamente de su obispo diocesano o de su superior, pueden colaborar en el trabajo pastoral del ordinariato. En tal caso, dependen del Ordinario en lo que concierne al encargo pastoral u oficio que reciben». Sin embargo, surge aquí una duda; si se aplicase este artículo, no cualquier ministro católico (no incardinado en un ordinariato) puede actuar como celebrante en el matrimonio de un fiel del ordinariato, sino sólo aquellos que colaboran establemente con un ordinariato «con el consentimiento escrito de su obispo diocesano o de su superior» (art. $9 \$ 2$ ). 
tamente, según las normas generales (cc. 1109, 1100 y 1111 y n. 5 de los tres primeros decretos de erección), un matrimonio entre fieles del ordinariato, puede hacerlo según este ritual aprobado para los ordinariatos aunque no pertenezca al ordinariato.

Por el contrario, si lo que efectivamente quieren señalar estos prenotanda es que cualquier clérigo «en caso de necesidad pastoral o de ausencia de un clérigo del ordinariato» puede asistir al matrimonio de dos fieles del ordinariato, entonces este n. 3 concreta un poco más el n. 5 de los decretos de erección y así, en casos de «necesidad pastoral» (es decir, en la práctica cualquier hecho razonable) o «ausencia de un clérigo incardinado en el ordinariato», no sería necesario recibir la facultad que prescribe el n. 5 de los decretos. Lógicamente esto generaría algunas dudas: la mayor es que unos prenotanda no pueden derogar la ley general. Por otro, que esta disposición sólo podría aplicarse si los dos son fieles del ordinariato ${ }^{78}$. Por último, dentro del concepto de «necesidad pastoral», realmente cabe cualquier cosa, así que en la práctica no sería necesario solicitar la facultad. Por eso me inclino por la conclusión de que es simplemente una concreción litúrgica.

Por último, y para concluir este apartado sobre el matrimonio, señalar también que los cc. $1077 \$ 1$ y $1078 \$ 1$ que establecen que el ordinario del lugar puede prohibir la celebración del matrimonio en un caso peculiar y dispensar de un impedimento matrimonial no reservado son aplicables a los fieles del ordinariato ${ }^{79}$ tanto por el obispo de la diócesis como por el ordinario del ordinariato personal.

\subsection{Sacramento del Orden}

Respecto al sacramento del Orden, si se considera que el ordinario local es también ordinario propio, entonces nada impide que el ordinario del lugar admita en su seminario como candidato a un fiel del ordinariato personal. Si se considerarse la jurisdicción del ordinariato como exclusiva para este ámbito, por comparación, se podría acudir al c. $1015 \$ 2$. Este canon establece que el obispo propio no puede ordenar a un súbdito si éste es de rito oriental, a no

${ }^{78}$ Ya que si uno no lo es, ya no es posible, pues el fiel que no fuera miembro del ordinariato, estaría sometido al derecho común y necesitaría la facultad del párroco territorial (c. 1111).

79 E. BAURA, Los decretos de erección de los Ordinariatos Personales para antiguos fieles anglicanos..., cit., 12 , nota 26. 
ser que haya obtenido indulto apostólico. «Es claro que un fiel del ordinariato no es de rito oriental, pero cabría preguntarse si el obispo diocesano es obispo propio, si por el hecho de que el fiel del ordinariato pertenece a una jurisdicción exclusiva, no lo es, de manera que para ordenarlo (e incardinarlo en la diócesis) es necesario antes que abandone el ordinariato ${ }^{80}{ }_{\gg}$. En todo caso, para abandonar un ordinariato, basta solicitarlo al ordinario. Entonces lo más indicado sería que ese fiel dejara de pertenecer al ordinariato mediante una solicitud al ordinario, en cuyo caso pasaría a depender automáticamente de la diócesis (cfr. art. 10 de los tres primeros decretos de erección). En todo caso, el Obispo propio para la ordenación diaconal es el del domicilio del ordenando o el de la circunscripción a cuyo servicio haya decidido dedicarse y en ella haya sido aceptado (c. 1016), «de manera que el criterio objetivo de adscripción o incardinación originaria de los clérigos es la ordenación diaconal, pero puede ordenarles para el servicio de su circunscripción el obispo que elijan y los acepte $^{81} \gg$.

\subsection{La sumisión judicial}

Se puede también analizar la posición del fiel con respecto a la diócesis, en función de la sumisión jurisdiccional. El art. XII de AC establece que:

«Para las causas judiciales, el tribunal competente es el de la diócesis donde tiene su domicilio una de las partes, a no ser que el ordinariato haya constituido un tribunal propio, en cuyo caso el tribunal de apelación será el designado por el ordinariato y aprobado por la Santa Sede. En ambos casos se tendrán en cuenta los distintos títulos de competencia establecidos por el Código de derecho canónico».

Para Baura, «la redacción de esta norma adolece de falta de precisión técnica, de manera que hay que interpretarla restrictivamente, presuponiendo que no pretende cambiar las reglas generales sobre el fuero competente (cc. 1408 y ss.) y, por tanto, que no se consagra la validez del fuero del actor a toda costa, pues sería contrario a los principios procesales fundamentales; de

80 E. BAURA, Los ordinariatos personales para antiguos anglicanos. Aspectos canónicos de la respuesta a los grupos de anglicanos que quieren incorporarse a la Iglesia católica..., cit., 263.

81 Cfr. J. Miras, La delimitación de las comunidades de fieles en la organización pastoral de la Iglesia. Observaciones sobre el sentido de los criterios objetivos que usa el derecho canónico..., cit., 60. 
hecho en nota a pie de página la Constitución Apostólica cita los cc. 14101414 y 1673, lo que parece indicar que el artículo no pretende derogar esas normas, no obstante su redacción textual ${ }^{82} \gg$.

Los decretos de erección parecen aportar un pequeño matiz que podría inclinar la balanza hacia la postura de que los fieles no pertenecen a la diócesis. Mientras que AC parece otorgar al tribunal de la diócesis la competencia sobre las causas de los fieles de un ordinariato (a no ser que el Ordinariato haya constituido un tribunal propio), en el n. 8 de los tres primeros decretos de erección se afirma que «mientras el Ordinariato personal de (...) no haya instituido su propio tribunal, las causas judiciales de sus fieles se deben llevar (are referred to) al tribunal de la diócesis en la que tenga su domicilio una de las partes ${ }^{83} \gg$. Es decir, no se señala directamente que el tribunal de la diócesis sea competente, sino simplemente que debe asumir esas causas. Sin embargo, el tribunal de la diócesis puede asumirlas porque es competente por un criterio general que entra en juego si no hay uno específico de la ley especial: De hecho, al igual que AC, los decretos hacen referencia a los cc. 1408-1414 y 1673 que establecen esos criterios generales, por lo que no parece que se quieran derogar esas normas. En este sentido creo que es interesante lo que señala Llobell. Para este autor, en el ámbito procesal, la denominación de «concurrente» para la coordinación de tribunales de estructuras personales y territoriales sería más correcta que la de «cumulativa»; «porque la potestad cumulativa implica la posibilidad del ejercicio simultáneo de dos o más jurisdicciones, mientras que la potestad concurrente afirma la competencia de varios tribunales, que, en todo caso, no puede ser ejercitada simultáneamente por el instituto de la prevención ${ }^{84} \gg$.

82 E. BAuRA, Los decretos de erección de los Ordinariatos Personales para antiguos fieles anglicanos, Revista General de Derecho Canónico y Derecho Eclesiástico del Estado 28 (2012), en www.iustel. com, 14.

83 Art. 8: «Until the Personal Ordinariate of (...) may have established its own Tribunal, the judicial cases of its faithful are referred to the Tribunal of the Diocese in which one of the parties has a domicile, while taking into account, however, the different titles of competence established in cc. 1408-1414 and 1673 CIC».

${ }^{84}$ J. LLOBELL, I tribunali delle circoscrizioni personali latine, Il Diritto Ecclesiastico 113/1 (2002) 147176, nota, 54. En la misma línea se manifiesta, P. MONETA, Territorialidad y personalidad en el sistema vigente de tutela de los derechos de los fieles, Ius Canonicum 42 (2002) 83-106, 90. Aunque para este autor, si bien la jurisdicción de los tribunales militares es concurrente con los territoriales, en el caso de las prelaturas personales: «La pertenencia a estas estructuras confiere al fiel una calificación personal específica que lo somete directamente, sin mediación alguna de localización territorial, al ordinario propio (el prelado), y por consiguiente al tribunal que, en nombre de éste, 


\section{OTRAS RELACIONES JURÍDICAS DEL FIEL DEL ORDINARIATO CON LA DIÓCESIS}

Además del matrimonio, el orden sacerdotal y la sumisión judicial, el hecho es que surgen relaciones jurídicas de los fieles de un ordinariato personal con la diócesis, lo que me parece que hace ver que un fiel del ordinariato estará sometido al ordinario local en diversos ámbitos.

En primer lugar, los fieles del ordinariato se encuentran sometidos a la ley universal (c. $12 \$ 1$ ), salvo casos de exención específica de una ley universal para un ordinariato personal ${ }^{85}$ (c. $12 \$ 2$ ). También los fieles de un ordinariato son por lo menos fieles actu degentes en el territorio diocesano y bajo este título son sujetos susceptibles de recibir algunos actos de la potestad ejecutiva del obispo de la diócesis donde tienen su domicilio ${ }^{86}$ o cuasidomicilio: Por ejemplo, las leyes particulares de la diócesis que se refieren al orden público son tuteladas por el obispo diocesano y obligan también a los fieles del ordinariato (c. $13 \$ 2,2^{\circ}$ ). El domicilio es una circunstancia que indudablemente forma parte del estado jurídico de la persona ${ }^{87}$, por eso, aunque la jurisdicción del ordinariato fuese declarada exclusiva, los fieles de un ordinariato están sometidos a algunas normas del territorio: aquellas que miran a la tutela del orden público, aquellas que determinan las formalidades que han de observarse en los actos o las que se refieren a las cosas inmuebles situadas en el territorio (c. $\left.13 \$ 2,2^{\circ}\right)$.

se destina al ejercicio de la función judicial» es decir, como calificándola de exclusiva. Aunque en el caso de la Prelatura Personal del Opus Dei, precisa que «la jurisdicción de este tribunal es concurrente con la del ordinario del lugar al que cualquier miembro de la prelatura continúa perteneciendo, pero con un régimen distinto del de los ordinariatos militares. Más que la prevalencia completa de una jurisdicción sobre la otra, ambas jurisdicciones se sitúan una junto a la otra, repartiéndose las materias: el tribunal de la prelatura tiene jurisdicción tan sólo para las materias que guardan relación con el fin de la prelatura misma, mientras que todo el resto permanece sometido a la jurisdicción general de los tribunales diocesanos». Ibid., 86 y 87 respectivamente a los textos citados. Por su parte, Baura, al referirse a los tribunales de los ordinariatos militares señala que la potestad judicial de estos órganos es cumulativa (cfr. E. BAURA, Legislazione sugli Ordinariati Castrensi, Giuffrè, Milán 1992, 35).

${ }^{85}$ Una ley universal podría no estar vigente en un ordinariato por costumbre contraria (con las características de una costumbre aprobada), por ley particular pontificia contraria, por privilegio o indulto apostólico. Cfr. J. OtAduY, Comentario al c. 12, en Á. MARZOA - J. Miras - R. RodríGUEZ-OCaÑa, Comentario Exegético al CIC, Eunsa, Pamplona 2002, vol. I, 329.

${ }^{86}$ E. BAURA, Los decretos de erección de los Ordinariatos Personales para antiguos fieles anglicanos..., cit., $12-13$

87 J. OTADUY, Territorialidad y personalidad son categorías jurídicas abiertas, Ius Canonicum 42 (2002) 13-39, 18. 
Asimismo -aparte del domicilio- por el hecho de estar o de vivir en un territorio, se encuentran también sometidos a las leyes particulares territoriales que no sean incompatibles con las del ordinariato: El art. 9 de los tres primeros decretos de erección establece expresamente que los fieles de un ordinariato personal que están temporal o permanentemente fuera del territorio de la Conferencia Episcopal donde ha sido erigido el ordinariato, permaneciendo como miembros del Ordinariato, están sometidos al derecho universal $\mathrm{y}$ a aquellas leyes particulares del territorio en el que se encuentren ${ }^{88}$.

De todas formas, aunque se declarase la jurisdicción del ordinario como exclusiva, pienso que esta disposición es aplicable también cuando se encuentran en el territorio de la Conferencia Episcopal donde ha sido erigido el ordinariato al que pertenecen ${ }^{89}$.

Además surgirán las relaciones jurídicas usuales por el mero hecho de que los fieles de un ordinariato acuden a la parroquia diocesana. Como comentamos antes, en la práctica se está dando el caso de fieles del ordinariato que bautizan a sus hijos en la parroquia diocesana y después solicitan para el niño la inscripción en el registro del ordinariato. En ese caso, el registro del bautismo queda en la parroquia diocesana, aunque después el niño sea también mimbro del ordinariato y sea inscrito en su registro.

Para concluir, me gustaría señalar que como estamos en los inicios de los ordinariatos aún quedan muchos puntos por concretar por la lógica novedad del fenómeno. Tal vez habrá también que explorar lo que señala el n. 16 de Communionis Notio que citábamos antes cuando establece que la pertenencia a las Iglesias particulares, «tiene diversas expresiones jurídicas (...) con la flexibilidad que le es propia ${ }^{90} \gg$. Con el tiempo, y con la experiencia de estos años

${ }^{88}$ Art. 9 DEPOOLW, DEPOTCSP, DEPOOLSC: «The faithful of the Personal Ordinariate of (OLW, TCSP, OLSC) who are, temporarily or permanently, outside the territory of the Episcopal Conference of (England and Wales, USA, Australia) while remaining members of the Ordinariate, are bound by universal law and those particular laws of the territory where they find themselves».

${ }^{89}$ Pensemos por ejemplo en un fiel del ordinariato de OLW que se encuentra en Inglaterra pero en una zona donde no puede acudir a una parroquia del ordinariato. Siguiendo el espíritu de este n. 9 de los decretos, pienso que debería someterse a las leyes de la diócesis donde se encuentre, y si por ejemplo, algún día es de precepto para esa diócesis particular, deberá cumplirlo, salvo, que la jurisdicción del ordinariato sea declarada exclusiva en el ámbito litúrgico cosa que no parece que vaya a ocurrir. Pensemos también el ejemplo contrario: Si -por ejemplo-, el día de la erección del ordinariato es declarado de precepto por el ordinario (c. $1244 \$ 2$ ), el fiel deberá cumplirlo allí donde se encuentre, aunque no esté dentro de los límites del territorio de la Conferencia Episcopal, ya que se trata de una disposición de carácter personal.

$90 \mathrm{CN} 16$, in fine. 
tal vez podrá concretarse mejor cuál es la expresión jurídica concreta de la pertenencia a la diócesis del territorio de un fiel de un ordinariato y podrá reflejarse en normas concretas.

El hecho de que la autoridad no haya tomado todavía expresamente una postura respecto a la cuestión de una posible jurisdicción exclusiva para los fieles de un ordinariato parece prudente, porque estamos aún ante una figura nueva y hay que esperar a ver cómo evoluciona, cómo se desarrollan las relaciones jurídicas de los fieles de un ordinariato con la diócesis y cuál es la mejor manera para articularlo. Si bien, como se ha comentado en estas páginas, pienso que una jurisdicción exclusiva sería otra fórmula jurídica que no haría que los fieles no pertenecieran a la diócesis en cuyo territorio están. Una declaración de exclusividad de la jurisdicción determinará en qué materias es exclusivamente competente el ordinario personal, lo que no excluye la pertenencia a la diócesis por el principio general de CN 16 y de los cc. 107 y $372 \$ 1$. 
JOSÉ MARÍA CHICLANA ÁCTIS

\section{Bibliografía}

ARrIETA, J. I., L'atto di erezione dell'opus Dei in prelatura personale, Apollinaris 56 (1983) 89-114.

—, Sulla natura giuridica degli Ordinariati personali, en AA.Vv., Sufficit Gratia Tua. Miscellanea in onore del Card. Angelo Scola per il suo $70^{\circ}$ compleanno, Marcianum Press, Venezia 2012, 67-79.

-, Prelatura personal, Revista General de Derecho Canónico y Eclesiástico del Estado 26 (2011) 1-17.

—, Gli Ordinariati personali, Ius ecclesiae 22 (2010) 151-172.

—, Il sistema dell'organizzazione ecclesiastica. Norme e documenti, Edusc, Roma 2006, 225-269.

-, Le prelature personali e le loro relazioni con le strutture territoriali, Il Diritto Ecclesiastico 112 (2001) 22-49.

BAURA, E., Los ordinariatos personales para antiguos anglicanos. Aspectos canónicos de la respuesta a los grupos de anglicanos que quieren incorporarse a la Iglesia católica, en C. PEÑa (ed.), Retos del derecho canónico en la sociedad actual, «Actas de las XXI Jornadas de Actualidad Canónica organizadas por la Asociación Española de Canonistas», Dykinson, Madrid 2012, 239-267.

—, Las circunscripciones eclesiásticas personales: el caso de los ordinariatos personales para fieles provenientes del anglicanismo, Ius Canonicum 50 (2010) 165-200.

—, Finalità e significato dell'erezione di una prelatura personale, en IDEM (a cura di), Studi sulla prelatura dell'Opus Dei. A venticunque anni dalla Costituzione apostolica «Ut sit», Edusc, Roma 2008, 35-67.

-, Le dimensioni «comunionali» delle giurisdizioni personali cumulative, en AA.VV., Territorialità e personalità nel diritto canonico e ecclesiastico. Il diritto canonico di fronte al terzo millenni. Atti del XI Congresso Internazionale di Diritto Canonico, Università Cattolica di Petro Pázmány, 2-7 settembre 2001, Budapest 2003, 427-439.

-, Le attuali riflessioni della canonistica sulle prelature personali: suggerimenti per un approfondimento realistico, en S. GHERRO, Le prelature personali nella normativa e nella vita della Chiesa, Venezia, Scuola Grande di San Rocco, 2526 giugno 2001, Padua 2002, 15-53.

Benedicto XVI, To the Catholic Bishops of England, Scotland and Wales, en M. Woodruff (ed.), Anglicans and Catholics in communion, editado por The Messenger of the Catholic League ${ }^{\circ}$ 292, Norfolk (enero 2011) 288.

BRAND, C., That Nothing Be Lost: America, Texas, and the Making of Anglicanorum Coetibus, Catholic southwest 22 (2011) 48-67. 
Burnham, A., The Personal Ordinariate of Our Lady of Walsingham, Pastoral Review, vol. 7, Issue 5 (2011) 2-27.

Chiclana, J. M., La Constitución Apostólica Anglicanorum Coetibus: Los ordinariatos personales para fieles provenientes del anglicanismo (Tesis de Doctorado, Universidad de Navarra, 4-X-2013).

-, Constitución Apostólica Anglicanorum Coetibus, 4-XI-2009, AAS 101 (2009) 985-990.

Congregación para la Doctrina De la Fe, Decreto de erección del Ordinariato personal de Nuestra Señora de la Cruz del Sur, 15-VI-2012, AAS 104 (2012) 600-603.

—, Decreto para el nombramiento del Ordinario personal de Nuestra Señora de la Cruz del Sur, 15-VI-2012, AAS 104 (2012) 599.

—, Decreto de erección del Ordinariato personal de la Cátedra de San Pedro, 1-I-2012.

—, Decreto de erección del Ordinariato personal de Nuestra Señora de Walshingham, 15-I-2011.

-, Complementary Norms to the Apostolic Constitution Anglicanorum Coetibus, 4XI-2009, AAS 101 (2009) 990-996.

-, Adnotatio circa Ordinariatum Personalem pro Anglicanis Catholicam Ecclesiam ingredientibus, 20 de octubre de 2009, AAS 101 (2009) 939-942.

—, Carta Communionis notio, AAS 85 (1993) 838-850.

Congregación para las Iglesias Orientales, Decreto Nobilis Gallice, de erección del Ordinariato para los fieles de rito oriental en Francia, $\$ \$ 5^{\circ}$ y $6^{\circ}$, AAS 47 (1955) 613.

-, Decreto Cum fidelium, de erección del ordinariato para los fieles de ritos orientales en Brasil, \$5, AAS 44 (1952) 382-383.

Congregación para los OBispos, Declaratio Praelaturae Personales sobre la erección del Opus Dei en Prelatura personal (23-VIII-1982), AAS 75 (1983) pars I, 464-468.

—, Decreto «Animarum Bonum» de erección de la Administración apostólica San Juan María Vianney, AAS 94 (2002) 305-307.

Díaz Moreno, J. M., Constitución «Anglicanorum Coetibus» sobre la institución de Ordinariatos personales para los anglicanos que ingresan en la plena comunión con la Iglesia, Revista española de derecho canónico 67, 168 (2010) 415-436.

Doe, N., The Apostolic Constitution Anglicanorum Coetibus: An Anglican Furidical Perspective, Ecclesiastical Law Journal 12 (2010) 304-332.

Galles, D., Anglicanorum Coetibus, some canonical investigations on the recent apostolic constitution, The Jurist 71 (2011) 201-233. 
Geldard, P., Conversion and enrichment, en S. CAVANaugh (ed.), Anglicans and the Roman Catbolic Church, Ignatius Press, San Francisco 2011, 40-63.

GHIRLANDA, G., Munus regendi et munus docendi dei conili particolari e delle conferenze dei vescovi, en AA.Vv., La Synodalité. Actes du VII congrés international de Droit Canonique, L'année canonique, hors série I (1992) 373-375.

—, La Costituzione Apostòlica Anglicanorum Coetibus, Periodica de re canonica 99 (2010) 373-430.

—, Il significato della costituzione apostolica Anglicanorum Coetibus, La Civiltà Cattolica, IV (2009) 385-392.

HeRvada, J., El Opus Dei erigido en prelatura personal, en IDEM, Vetera et Nova: cuestiones de Derecho canónico y afines (1958-2004), Navarra Gráfica Ediciones, Pamplona 2005.

Huels, J. M., Anglicanorum Coetibus; Text and Commentary, Studia Canonica 43 (2009) 389-430.

-, Canonical comments on Anglicanorum Coetibus, Worship-Collegeville 84 (2010) 237-253.

Jeremy, A., Apostolic Constitution Anglicanorum Coetibus and personal ordinariate of Our Lady of Walsingham, Revista Cristianessimo nella Historia 32 (2011) 425-442.

JUAN PABlo II, Constitución Apostólica Ut sit (28 de noviembre de 1982), AAS 75 (1983) 423-425.

—, Codex Particularis Operis Dei, en X. OcHOA, Leges Ecclesiae, Roma, vol. VI, 1987, n. 4938, colls. 8504-8531.

LANDETE CASAS, L., La atención pastoral de los fieles tradicionalistas: garantías para su plena inserción en la communio ecclesiastica, Fidelium Iura 11 (2001) 169-192.

Le Tourneau, D., La jurisdiction cumulative de l'Ordinariat aux Armées, Revue de Droit Canonique 37 (1987) 171-214.

Llobell, J., I tribunali delle circoscrizioni personali latine, Il diritto ecclesiastico 113 (2002) 147-176.

Marzoa, Á. - Miras, J. - Rodríguez-Ocaña, R., Comentario Exegético al CiC, Eunsa, Pamplona 2002.

Miras, J., Naturaleza jurídica de la potestad normativa de las Conferencias Episcopales según el CIC 83, en AA.Vv. - P. RodRíGUEZ (ed.), Iglesia Universal e Iglesias particulares. IX Simposio Internacional de Teología de la Universidad de Navarra, Servicio de Publicaciones de la Universidad de Navarra, Pamplona 1989, 677-692. 
-, Notas sobre la naturaleza de las prelaturas personales. A propósito de un discurso de Fuan Pablo II, Ius Canonicum 42 (2002) 363-388.

-, Organización territorial y personal: fundamentos de la coordinación de los pastores, en Aa.Vv. - J. CANOSA (ed.), I principi per la revisione del Codice di diritto canonico, Giuffrè, Milano 2000, 625-666.

Moneta, P., Territorialidad y personalidad en el sistema vigente de tutela de los derechos de los fieles, Ius Canonicum 42 (2002) 83-106.

Navarro, L., Persone e soggetti nell diritto della Chiesa. Temi di diritto della persona, Edusc, Roma 2000, 235 pp.

OdDIE, W., The Roman Option, Harper Collins, Londres 1997, 256 pp.

ÖrsY, L., Una fase di transicione, riflessioni di un canonista sulla Costituzione Apostolica Anglicanorum Coetibus, Revista Il Regno. Attualitá 2 (2010) 17.

OTADUY, J., Territorialidad y personalidad son categorías jurídicas abiertas, Ius Canonicum 42 (2002) 13-39.

Parlato, V., Note sulla Costituzione apostolica Anglicanorum Coetibus, Stato, Chiese e pluralismo confessionale, Revista telematica (www.statoechiese.it/ images/stories/2010.01/parlato_note.pdf) 9 (acceso 25/2/2016).

Passicos, J., L'ordinariat des catholiques de rite oriental résidant en France, L'année canonique 40 (1998) 151-163.

Personal Ordinariate of the Chair of St. Peter, Manual ministry, Abridge Ministry Handbook, Pro Manuscripto.

PuIG, F., Dimensione missionaria degli ordinariati personali, Ius Ecclesiae 26 (2014) 697-710.

READ, G., Anglicanorum Coetibus - a year of developments. Coment on de Decre of Erection of the Personal Ordinariate of Our Lady of Walsingham, Newsletter n. 165 de la Canon Law Society of Great Britain and Ireland, March 2011, 8-16.

Real Academia Española - Consejo General del Poder Judicial, Ordinariato personal para fieles anglicanos recibidos en la Iglesia católica, en REAL Academia Española - Consejo General del Poder Judicial, Diccionario del español jurídico, Espasa, Madrid 2016, 1147.

Renken, J., The Personal Ordinariate of the Chair of St. Peter, Studia Canonica 46 (2012) 5-50.

Sheehan, J. M., A new canonical configuration for the Pastoral Provision for former episcopalians in the United States of America?, Tesi di Dottorato discussa nella Facoltà di Diritto Canonico della Pontificia Università della Santa Croce, Roma 2009. 
Soler, C., Furisdicción cumulativa, Ius Canonicum 28 (1988) 131-180.

-, La jurisdicción cumulativa como manifestación de la communio potestatum. Una bipótesis sobre la potestad en los entes jerárquicos no eclesioparticulares, en VI INTERNATIONALEN KONGRESSES FÜR KANÖNISCHES RECHT (coord.), Das Konsoziative Element in der Kirche Akten, Eos Verlag, St. Ottilien 1989, 321-330.

Steenson, J. N., Statement on Creation of Ordinariate in U.S. for Former Anglicans, 2 January 2012, Origins 41 (2011-2012) 501.

Sullings, P., The Pastoral Provision Priests in the American Catholic Presbyterate (pro manuscripto).

SzCZEPANIUK, D., Situación canónica de los fieles laicos en las circunscripciones personales, Cuadernos Doctorales: Excerpta et Dissertationibus in Iure Canonico 22 (2007/2008) 201-238.

Tighe, W., The Genesis of Anglicanorum Coetibus, Anglican Embers, vol. III, number 8, advent 2011, 347-364.

VIANA, A., Territorialidad y personalidad en la organización eclesiástica. El caso de los Ordinariatos militares, Servicio de Publicaciones de la Universidad de Navarra, Pamplona 1992, 312 pp.

-, Complementariedad y coordinación entre los ordinariatos militares y las diócesis territoriales, Fidelium Iura 12 (1992) 241-275.

—, Organización del gobierno en la Iglesia, Eunsa, Pamplona 2010, 314 pp.

—, Ordinariatos y Prelaturas personales. Aspectos de un diálogo doctrinal, Ius Canonicum 52 (2012) 481-520.

WeBER, R., Das Volk als Strukturelement der kirchlichen Zirkumskription, Archiv für katholisches Kirchenrecht 181 (2012) 136-138.

Woodruff, M., Anglicans and Catholics in communion, editado por The Messenger of the Catholic League, $\mathrm{n}^{\circ}$ 292, Norfolk 2011.

ZAYDIN LABRID, P., Colección de breves y rescriptos pontificios de la jurisdicción eclesiástica castrense de España, Calpe, Madrid 1925, 21-33. 